\title{
O CURRÍCULO DE CIÊNCIAS NA BASE NACIONAL COMUM CURRICULAR
}

\section{THE SCIENCE CURRICULUM IN THE COMMON NATIONAL CURRICULUM BASE}

\author{
Luciane da Silva Vicente \\ Doutoranda em Educação pela Universidade Nove de Julho \\ Professora nas Redes Estadual e Municipal de São Paulo - SP - Brasil \\ lusivisv@hotmail.com
}

\begin{abstract}
Resumo: $\mathrm{O}$ presente artigo apresenta uma análise das referências curriculares propostas pela Base Nacional Comum Curricular (BNCC) para os anos finais do Ensino Fundamental na área de Ciências da Natureza. O objetivo desta análise é evidenciar o que vem sendo conduzido no espaço de autonomia dos sistemas educativos no que se refere às orientações curriculares encaminhadas para as instituições de ensino e de problematizar o processo de formulação do documento no contexto das políticas educacionais atuais. Assim, as ideias aqui desenvolvidas, terão como foco duas questões: o caráter oficial da BNCC e a relação de sintonia e legitimidade das orientações que a fundamentam com princípios e práticas já presentes no contexto escolar.
\end{abstract}

Palavras-chave: BNCC. Ciências. Currículo.

Abstract: The present article presents an analysis of the curricular references proposed by the Common National Curricular Base (BNCC) for the final years of elementary school in the area of Natural Sciences. The objective of this analysis is to highlight what has been conducted in the autonomy of the educational systems regarding the curricular guidelines sent to educational institutions and question the process of formulating the document in the context of current educational policies. Thus, the ideas developed here will focus on two main issues: the official status of the BNCC and the relationship of consistency and legitimacy of the guidelines that structure it with principles and practices already present in the school context.

Keywords: BNCC. Sciences. Curriculum.

\section{Introdução}

s ideias aqui apresentadas foram estruturadas a partir da leitura de documentos
elaborados pela Secretaria de Educação Básica do Ministério da Educação (MEC), do
exame da segunda e da terceira versão da Base Nacional Comum Curricular (BNCC) e da participação no Seminário Estadual da BNCC ocorrido em São Paulo¹. As reflexões aqui levantadas têm o propósito de evidenciar o que vem sendo conduzido no espaço de autonomia dos sistemas educativos no que se refere às orientações curriculares encaminhadas para as instituições de ensino e de problematizar o processo de formulação do documento no contexto das políticas educacionais atuais.

A criação de um currículo nacional unificado, proposto pelo Plano Nacional de Educação (PNE) Lei n ${ }^{\circ}$ 13.005/2014 - afirma a necessidade e a obrigação do Estado de elaborar parâmetros claros no campo curricular, capazes de orientar as ações educativas do ensino obrigatório, de forma a adequá-lo aos ideais democráticos e à busca da melhoria da qualidade do ensino nas escolas brasileiras (BRASIL, 2014). Com a finalidade de definir um ponto de equilíbrio entre orientações gerais e as listas prescritivas de conteúdos, o PNE determina entre União, Estados, Distrito Federal e Municípios, a implantação de direitos e objetivos 
de aprendizagem que configurarão a Base Nacional Comum Curricular (BNCC) na Educação Básica no âmbito da instância permanente.

A Base Nacional Comum Curricular (BNCC) começou a ser formulada no primeiro semestre de 2015. Em seu processo de construção e organização, reúnem membros de associações representativas das diversas áreas do conhecimento de Universidades públicas, do Conselho Nacional dos Secretários de Educação (CONSED), da União Nacional dos Dirigentes Municipais da Educação (UNDIME) e, fundamentalmente, representantes da classe empresarial - que incluem diversas organizações prestadoras de serviços pedagógicos - e a ONG Movimento pela Base Nacional Comum.

Entre setembro de 2015 e março de 2016 a primeira versão da BNCC é disponibilizada na internet para consulta pública. Nesse interstício a BNCC foi objeto de um amplo processo de debate e negociação, recebendo mais de 12 milhões de contribuições de diferentes entidades do campo educacional e da sociedade brasileira.

Publicada em maio de 2016, a proposta preliminar da segunda versão da BNCC, coordenada pelo CONSED e pela UNDIME, passou por um amplo processo de debate institucional em seminários realizados pelas Secretarias Estaduais de Educação em todas as Unidades da Federação (BRASIL, 2016). Segundo dados apresentados pela segunda versão revista da BNCC, nos seminários estaduais houve a participação de mais de "9 mil professores, gestores, especialistas e entidades de educação, encerrando o ciclo de consulta previsto para a esta versão do documento” (BRASIL, 2017, p. 5). Com base na análise realizada pela Universidade de Brasília (UnB), os resultados dessa discussão foram sistematizados e organizados em relatório, originando a terceira versão do documento que após passar por mais uma revisão foi aprovada pelo Conselho Nacional de Educação (CNE) e homologada pelo MEC em dezembro de 2017.

A versão final da BNCC traz em seu bojo o conjunto orgânico e progressivo de aprendizagens essenciais que todos os estudantes devem desenvolver ao longo da sua escolaridade na Educação Básica. Somando-se a esses propósitos, o documento estrutura-se em dez competências gerais que "pretendem assegurar, como resultado do seu processo de aprendizagem e desenvolvimento, uma a formação humana integral e a construção de uma sociedade justa, democrática e inclusiva” (BRASIL, 2017, p. 25).

Em linhas gerais, o documento incorpora os princípios já preconizados nos Parâmetros Curriculares Nacionais (PCN) - última referência curricular para todo o ensino básico - e apresenta três divisões que coloca os conteúdos disciplinares a serviço da aprendizagem de competências, visando atender às diferenças individuais dos estudantes:

1. Foco no desenvolvimento de competências - por meio da indicação clara do que os alunos devem “saber" (considerando a constituição de conhecimentos, habilidades, atitudes e valores);

2. Compromisso com a Educação integral - que deve visar à formação e o desenvolvimento humano global dos estudantes, em sua dimensão intelectual, social, emocional, física e cultural; 
3. Igualdade, diversidade e equidade - que devem valer para as oportunidades de ingresso e permanência em uma escola de Educação Básica, assim como, reconhecer que as necessidades dos estudantes são diferentes.

\section{As referências da BNCC para o currículo de ciências}

No que tange ao currículo de Ciências da Natureza, a BNCC preconiza o compromisso dessa disciplina com a capacidade de compreender, interpretar e transformar o mundo (natural, social e tecnológico) com base em aportes teóricos orientadas para o desenvolvimento de competências essenciais ao exercício pleno da cidadania. Considerando tais pressupostos, o componente curricular de Ciências, conforme postula a BNCC, deve garantir aos estudantes o desenvolvimento das seguintes competências específicas:

1. Compreender as Ciências da Natureza como empreendimento humano, e o conhecimento científico como provisório, cultural e histórico.

2. Compreender conceitos fundamentais e estruturas explicativas das Ciências da Natureza, bem como dominar processos, práticas e procedimentos da investigação científica, de modo a sentir segurança no debate de questões científicas, tecnológicas, socioambientais e do mundo do trabalho, continuar aprendendo e colaborar para a construção de uma sociedade justa, democrática e inclusiva.

3. Analisar, compreender e explicar características, fenômenos e processos relativos ao mundo natural, social e tecnológico (incluindo o digital), como também as relações que se estabelecem entre eles, exercitando a curiosidade para fazer perguntas, buscar respostas e criar soluções (inclusive tecnológicas) com base nos conhecimentos das Ciências da Natureza.

4. Avaliar aplicações e implicações políticas, socioambientais e culturais da ciência e de suas tecnologias para propor alternativas aos desafios do mundo contemporâneo, incluindo aqueles relativos ao mundo do trabalho.

5. Construir argumentos com base em dados, evidências e informações confiáveis e negociar e defender ideias e pontos de vista que promovam a consciência socioambiental e o respeito a si próprio e ao outro, acolhendo e valorizando a diversidade de indivíduos e de grupos sociais, sem preconceitos de qualquer natureza.

6. Utilizar diferentes linguagens e tecnologias digitais de informação e comunicação para se comunicar, acessar e disseminar informações, produzir conhecimentos e resolver problemas das Ciências da Natureza de forma crítica, significativa, reflexiva e ética.

7. Conhecer, apreciar e cuidar de si, do seu corpo e bem-estar, compreendendo-se na diversidade humana, fazendo-se respeitar e respeitando o outro, recorrendo aos conhecimentos das Ciências da Natureza e às suas tecnologias.

8. Agir pessoal e coletivamente com respeito, autonomia, responsabilidade, flexibilidade, resiliência e determinação, recorrendo aos conhecimentos das Ciências da Natureza para tomar decisões frente a questões científico-tecnológicas e socioambientais e a respeito da saúde individual e coletiva, com base em princípios éticos, democráticos, sustentáveis e solidários (BRASIL, 2017, p. 322).

As aprendizagens consideradas essenciais neste componente curricular foram organizadas em três grandes unidades temáticas que se repetem ao longo de todo o Ensino Fundamental:

a) Matéria e energia - contempla o estudo de materiais e suas transformações, fontes e tipos de energia utilizados na vida em geral, na perspectiva de construir conhecimento sobre a natureza da matéria e 
os diferentes usos da energia.

b) Vida e evolução - propõe o estudo de questões relacionadas aos seres vivos (incluindo os seres humanos), suas características e necessidades, e a vida como fenômeno natural e social, os elementos essenciais à sua manutenção e à compreensão dos processos evolutivos que geram a diversidade de formas de vida no planeta.

c) Terra e Universo - busca-se a compreensão de características da Terra, do Sol, da Lua e de outros corpos celestes - suas dimensões, composição, localizações, movimentos e forças que atuam entre eles (BRASIL, 2017).

Atrelado às essas três grandes temáticas, a BNCC em sua versão final, apresenta um conjunto de habilidades que os alunos devem desenvolver em cada um dos nove anos de permanência no Ensino Fundamental. As habilidades incorporam os conhecimentos considerados essenciais para desenvolver o letramento científico, possibilitando que os estudantes "tenham um novo olhar sobre o mundo que os cerca, como também façam escolhas e intervenções conscientes e pautadas nos princípios da sustentabilidade e do bem comum” (BRASIL, 2017, p. 319).

Segundo o pesquisador Nélio Bizzo (Faculdade de Educação - USP) em entrevista no canal UNIVESP (2015), as principais críticas sobre o currículo de ciências na BNCC residem em pretender sincronizar o ensino de ciências no Brasil inteiro, ou seja, determinar o que vai ser ensinado a cada ano, a cada bimestre ou até mesmo a cada semana. Para esse pesquisador, o ensino de certos conceitos, como atividades de experimentação em determinadas épocas do ano, são inviáveis, pois as condições de temperatura e umidade que variam no país, interferem nos resultados e consequentemente na abstração dos conceitos por parte dos estudantes.

Ainda conforme o posicionamento do referido pesquisador, a tradição das Diretrizes Curriculares Nacionais (DCN) em estabelecer princípios mais gerais para a organização dos currículos, deve ser mantida, pois quanto maior o nível de detalhamento de uma proposição curricular, menor será a probabilidade de atingir seus propósitos. Não basta jogar sementes ao vento, épreciso saber se o que está sendo feito de fato funciona ${ }^{2}$.

Diferentemente do que contestam os especialistas na proposta da BNCC para a disciplina de História, não se observa nas Ciências da Natureza um viés ideológico dos conteúdos no sentido de privilegiar temas ligados aos interesses da direita conservadora ou da esquerda progressista/popular. Contudo, o conjunto dos conhecimentos conceituais selecionados para o ensino de Ciências é organizado na BNCC em unidades temáticas que não dialogam entre si, sendo pouco adequado para a compreensão determinados conceitos por parte dos estudantes.

A nosso ver, a proposição de um currículo mínimo deveria centrar-se em conceitos disciplinares que estabelecessem uma coerência de compatibilidade entre si e não reunir um conjunto de tópicos desarticulados sobre temáticas diversas. Essa forma de organização curricular, além de ocasionar o tratamento superficial dos chamados conteúdos essenciais, poderá acarretar a compartimentalização dos saberes 
escolares, contrapondo-se, inclusive, aos aspectos centrais da interdisciplinaridade, defendida por especialistas como ferramenta substancial para compreensão integral do fenômeno estudado.

No que se refere ao ensino e aprendizagem de Ciências, nota-se que não foram mencionadas as referências teóricas que embasaram a construção do documento. Por não se tratar de um trabalho científico, não seriam necessárias muitas citações, mas algumas poucas referências deveriam estar explícitas a fim de favorecer a compreensão do que está sendo proposto.

Em continuidade à nossa análise, observa-se que a BNCC apresenta uma proposta curricular centrada em objetivos de aprendiragem, os quais são estruturados nos chamados contéidos mínimos. Porém, de forma engessada, conteudista e com pouco espaço para ação docente, o que coloca escolas em condições distintas de realizar o que está definido. Como se em qualquer turma, de qualquer contexto social, o professor encontrasse condições idealizadamente semelhantes sobre as quais se possam trabalhar tais objetivos.

A nosso ver, essa centralidade nos objetivos de aprendizagem aparenta ser mais uma forma de controlar o trabalho docente, do que supostamente assegurar a aprendizagem dos estudantes. Se o direito à aprendizagem está prescrito na legislação educacional, a autonomia pedagógica também está.

Além dos conteúdos mínimos, que correspondem a $60 \%$ dos conhecimentos que deverão compor os currículos de todo território nacional, o documento BNCC apresenta a chamada parte diversificada, que representa $40 \%$ do currículo a ser adequado à realidade local. No entanto, essa perspectiva é mais uma utopia. Uma vez que se propõem habilidades tão específicas, carregadas de conteúdos disciplinares, suprimem-se as condições de trabalho sobre as quais é possível implementar essas adequações.

Mesmo que os currículos sejam adequados à realidade de cada escola, as avaliações externas passam a ser referenciadas nessa base. Ao vincular a BNCC aos exames nacionais, os $60 \%$ obrigatórios tendem a se converterem nos 100\% do ensino nas escolas, prejudicando assim, os trabalhos adaptados aos currículos locais.

Outro ponto que chamou nossa atenção na BNCC foi a ausência dos chamados temas transversais introduzidos pelos PCN do Ensino Fundamental no contexto das reformas curriculares dos anos 1990. Ainda que tal proposição necessitasse ser reestruturada, a concepção de transversalidade trazia para as escolas a proposta de um trabalho coletivo na abordagem de temas socialmente relevantes. Na BNCC esses temas estão distribuídos nas disciplinas específicas com articulações que nem sempre são perceptíveis pelos professores, o que dissimula a importância de se estabelecer conexões com as diferentes áreas do conhecimento.

Uma vez que, na última década, questões culturais, relações de gênero e étnico-raciais vieram progressivamente sendo incorporadas aos currículos, também ganharam espaço nas primeiras versões da BNCC. No entanto, com a justificativa de que a temática gênero provocara muita controvérsia o MEC eliminou da versão final os termos gênero e orientação sexual, restringindo-se ao termo sexualidade. As 
argumentações afirmam que esses conteúdos provocariam uma crise de identidade e um processo de assujeitamento, que poderiam afetar a família e a integridade moral e intelectual dos jovens.

Na proposição curricular para o ensino de ciências é também identificada na BNCC a ausência de perspectivas sociais relativas à sexualidade e à reprodução humana. Dimensões estas, de suma importância para os estudantes, desde os 10 - 11 anos e que estão sendo apresentadas na BNCC de forma muito simples e talvez tardia, apenas no $8^{\circ}$ ano, o que é um retrocesso em relação aos Parâmetros Curriculares Nacionais.

Se o estudo do corpo humano vem sendo tradicionalmente contemplado em um único ano de escolaridade ( $8^{\circ}$ ano) e ainda assim o desafio da integração está posto, com a não distribuição desse tema ao longo do $6^{\circ}$ ao $9^{\circ}$ ano, essa fragmentação é potencialmente ampliada.

Reconhecemos que não há um arranjo curricular ideal e que toda e qualquer configuração proposta acaba sempre destacando determinados aspectos e esvaziando outros. Ainda assim, no que diz respeito aos conhecimentos relativos ao corpo humano, a proposta BNCC precisa ser reformulada, sobretudo por caminhar em sentido oposto a algumas convicções produzidas em debates acadêmicos na comunidade do Ensino de Ciências.

Embora a BNCC apresente uma concepção curricular comprometida com a educação integral, há outras questões não esclarecidas que precisam ser analisadas e debatidas. Lembremos também da necessidade de alinhamento dos livros didáticos selecionados pelo governo e dos programas de avaliação com a Base Nacional. Tudo isso foi ignorado na época da elaboração dos Parâmetros Curriculares Nacionais, o que, certamente, determinou seu pouco enraizamento nas salas de aula.

\section{Considerações finais}

A discussão realizada neste texto nos permite apontar considerações importantes, quando pensamos em Base Nacional Comum Curricular. Dentre elas, destacamos a importância da participação da sociedade na discussão do currículo Nacional como forma de saber o que a escola faz e o que se pode esperar dela, principalmente, em relação à qualidade de ensino e da aprendizagem.

Contudo, a BNCC por si só, de nada valerá se os professores não estiverem preparados e apoiados para garantir o desenvolvimento das habilidades e aprendizagens descritas nela. Em vista disso, precisamos primeiramente questionar se as condições necessárias para a implementação da BNCC serão garantidas para que de fato contribua para a melhor condução do trabalho docente.

Como a escola receberá tal documento? Existirá de fato um espaço para as particularidades locais de cada instituição? Qual impacto desse documento sobre os trabalhos já consolidados pelos currículos locais? Quais critérios balizarão potencial de promover mudanças significativas na educação brasileira? A escuta a alunos, professores, gestores e especialistas será mantida após a implementação da BNCC? O que 
será feito em termos de política educacional, para proporcionar condições estruturais, materiais e humanas para garantia do direito à aprendizagem?

Assim, ressaltamos a importância do Projeto Político-Pedagógico (PPP) na caracterização e identidade das escolas, não podendo esse projeto ser postergado na escolha curricular. Essa autonomia é de fundamental importância para a construção curricular, pois além de levar em conta as particularidades de cada escola, evitam-se interferências excessivamente subjetivas e pessoais dos que não fazem parte dela.

Notas

${ }^{1}$ Refere-se ao Seminário Estadual sobre a $2^{\mathrm{a}}$ versão da BNCC - realizado nos dias 27 e 28 de julho de 2016 na Escola de Formação e Aperfeiçoamento dos Professores da Secretaria Estadual de Educação de São Paulo.

2 Expressão utilizada pelo pesquisador Nelio Bizzo (Faculdade de Educação - USP) em entrevista do canal UNIVESP em 04 de dezembro de 2015.

\section{Referências}

BRASIL. Ministério da Educação. Base Nacional Comum Curricular. Proposta preliminar. Segunda versão revista. Brasília: MEC, 2016.

BRASIL. Ministério da Educação. Base Nacional Comum Curricular. Terceira versão revista. Brasília: MEC, 2017. Disponível em < http://basenacionalcomum.mec.gov.br/wpcontent/uploads/2018/04/BNCC_19mar2018_versaofinal.pdf > acesso em 29/05/2018.

BRASIL. Secretaria de Articulação com os Sistemas de Ensino. Planejando a Próxima Década: Conhecendo as 20 Metas do Plano Nacional de Educação. MEC/SASE, 2014.

BRASIL. Plano Nacional de Educação 2014-2024. Brasília: Edições Câmara, 2014. Disponível em < http://www.observatoriodopne.org.br/uploads/reference/file/439/documento-referencia.pdf $>$ acesso em 29/05/2018.

UNIVESP, Canal. Desafios da Educaşão: Especial - O currículo de Ciências na Base Nacional Comum Curricular. São Paulo, 4 de dez de 2015.Vídeo (canal virtual) - 29:59 min. Disponível em < https://www.youtube.com/watch?v=yESytG_O9pE> acesso em 29/05/2018.

Recebido em: 21 out. 2018 / Aprovado em: 29 out. 2019

\section{Para referenciar este texto}

VICENTE, Luciane da Silva. O currículo de ciências na base nacional comum curricular. Cadernos de Pósgraduação, São Paulo, v. 18, n. 2, p. 04-10, jul./dez. 2019. Disponível em: $<$ https://doi.org/10.5585/cpg.v18n2.10792>. 